Article

\title{
Evaluation and Analysis of Noise and Vibration Exposure Level on Operator of QT40B, QTJ4-40, Lister and LM2-45 Block Moulding Machine
}

\author{
Amine, J. D 1, Sampson Chisa Owhor ${ }^{2,}$, Milkail Alhaji Abdulkareem ${ }^{2}$ \\ ${ }^{1}$ Department of Mechanical Engineering, University of Agriculture Makurdi, Benue State, Nigeria \\ 2 Department of Mechanical Engineering, Federal University Wukari, Taraba State, Nigeria \\ ${ }^{*}$ Correspondence: owhorchisa@gmail.com
}

How to cite this paper: Amine, J. D., Owhor, S.C., \& Abdulkareem, M.A. (2021). Evaluation and Analysis of Noise and Vibration Exposure Level On Operator of QT40B, QTJ440, Lister and LM2-45 Block Moulding Machine. Online Journal of Mechanical Engineering, 1(1), 1-9. Retrieved from https://www.scipublications.com/journal/in-

dex.php/ojme/article/view/70

Received: July 1, 2021

Accepted: August 11, 2021

Published: August 12, 2021

Copyright: $\odot 2021$ by the authors. Submitted for possible open access publication under the terms and conditions of the Creative Commons Attribution (CC BY) license (http://creativecommons.org/licenses /by/4.0/).

\begin{abstract}
High levels of occupational noise and vibration remain a problem in all regions of the world. In Nigeria, $12-15 \%$ of the workforce are exposed to these hazards by WHO, 2001. This research intends to achieve the following objectives; To assess the noise emitted during the moulding of various types of blocks, to determine the level of vibration induced to workers of block moulders during activities and to determine the effect of noise and vibration on workers. The following materials and equipment were used; QT40B manual block moulding machine, LM2-45 Mobile Block moulding Machine, Lister powered block moulding machine, QTJ4-40 block moulding machine using 9 and 6 inches Plates, Vibrometer and Noise monitor. The workers were exposed to noise levels above $75 \mathrm{~dB}$ and vibration levels above $5 \mathrm{~ms}-2$ set as upper limit values in the Directive 44/EC from 2002 - on the Minimum Health and safety Requirements Regarding to Exposure of Workers to the Risk Arising from Physical Agents Vibration.
\end{abstract}

Keywords: Block, Moulding Machine, Noise, Operator Vibration

\section{Introduction}

Physically, there is no difference between sound and noise. Sound is a sensory perception and noise corresponds to undesired sound. By extension, noise is any unwarranted, disturbance within a useful frequency band [1]. Noise is present in every human activity, and when assessing its impact on human well-being, it is usually classified either as occupational noise (i.e. noise in the workplace), or as environmental noise, which includes noise in all other settings, whether at the community, residential, or domestic level (e.g. traffic, playgrounds, sports, music).

Noise is a prevalent exposure in many workplaces. According to [2], approximately nine million workers in the USA alone are exposed to time-weighted average (TWA) sound levels of $85 \mathrm{~dB}(\mathrm{~A})$ and above. Exposure is especially prevalent in mining, manufacturing, and the construction industry [3].

Construction workers are still considered as an underserved population where it comes to hearing loss prevention with one in twenty construction workers estimated to have occupational hearing loss $[3,4]$. Although noise is associated with almost every work activity, some activities are associated with particularly high levels of noise, the most important of which are working with impact processes, handling certain types of materials, and flying commercial jets. Occupations at highest risk occupational noise and vibration exposure (ONVE) include those in manufacturing, transportation, mining, construction, agriculture and the military.

The situation is improving in developed countries; as more widespread appreciation of the hazard has led to the introduction of protective measures. Data for developing 
countries are scarce, but available evidence suggests that average noise levels are well above the occupational level recommended in many developed nations $[5,6]$. The average noise levels in developing countries may be increasing because industrialization is not always accompanied by protection.

There are therefore several reasons to assess the burden of disease from occupational noise and vibration exposure at country or subnational levels. Occupational noise and vibration exposure is a widespread risk factor, with a strong evidence base linking it to an important health outcome (hearing loss) [7].

It is also distinct from environmental noise, in that it is by definition associated with the workplace, and is therefore the responsibility of employers as well as individuals.

An assessment of the burden of disease associated with occupational noise can help guide policy and focus research on this problem. This is particularly important in light of the fact that policy and practical measures can be used to reduce exposure to occupational noise [8]. Due to the setting and nature of the job noise exposure varies over time and there are often combined exposures such as chemicals and vibration. Various trades work in the same environment which puts also quiet trades at risk. Communication and sound localization are of vital importance for the workers but personal hearing protection devices can degrade those abilities.

Vibration refers to the "oscillatory motions of solid bodies arises from mechanical sources with which humans have physical contact" $[9,10]$ describes two main types of vibration exposure: "whole body vibration- the body is shaken by a machine or vehicle" and "hand-arm vibration-where the vibration effect is localized to the hand and arm." According to $[9,10]$ "Occupational exposures to whole-body vibration mainly occur in transport but also in association with some industrial processes." Generally, exposures to hand-arm vibration are associated with "vibration of hand-held tools and work pieces.

In 2008, the Australian Safety and Compensation Council declared ONIHL to be one of eight priority diseases that must be addressed by regulators and industry [11]. The report work-related Noise Induced Hearing Loss in Australia [11] estimated about 1 million employees in Australia were exposed to hazardous levels of noise (in the absence of hearing protection), accounting for about $16 \%$ of adult-onset hearing loss. The occupational groups most affected were blue-collar workers such as laborers, trades persons, and plant or machine operators. The 2003 Australian Bureau of Statistics' Survey of Disability, Ageing and Careers revealed that people with hearing loss were less likely to be found in highly skilled jobs and were overrepresented among low-income earners [12].

\section{Materials and Methods}

\subsection{QT40B manual interlock making machine}

The noise produced by QT40J manual interlocking making machine was measured three time for the duration of 20 second and recorded. The background noise, the idle noise produced, the production noise produced was measured and recorded, using noise meter.

The background and idle noise is recorded using the sound level meter, the idle noise can be calculated using equation 1 .

$$
\text { Idle noise }\left(\mathrm{IN}_{\mathrm{N}}\right)=\mathrm{N}_{\mathrm{M}}+\mathrm{B}_{\mathrm{N}}
$$

Where:

$\mathrm{IN}_{\mathrm{N}}=$ Idle noise

$\mathrm{N}_{\mathrm{M}}=$ Machine noise

$\mathrm{B}_{\mathrm{N}}=$ background noise

The overall noise was calculated using equation 2 . 


$$
\mathrm{O}_{\mathrm{N}}=\mathrm{IN}_{\mathrm{N}}+\mathrm{P}_{\mathrm{N}}
$$

Or

$$
\mathrm{O}_{\mathrm{N}}=\mathrm{NM}_{\mathrm{M}}+\mathrm{B}_{\mathrm{N}}+\mathrm{P}_{\mathrm{N}}
$$

Where

$\mathrm{O}_{\mathrm{N}}=$ Overall noise

$\mathrm{IN}_{\mathrm{N}}=$ Idle noise

$\mathrm{P}_{\mathrm{N}}=$ Production noise

This procedure was used repeated using vibrometer to measure vibrations generated during each of the processes.

\subsection{LM2-45 mobile block moulding machine}

The noise induced by LM2-45 mobile block moulding machine was taken for the duration of 20 seconds and recorded. The idle noise produced on LM2-45 mobile block moulding machine was measured and recorded. The production noise was measured on LM2-45 mobile block moulding machine and recorded. The vibration produced by LM245 block moulding machine were measured three times for duration of 20 seconds and recorded. The vibration was taken axially, horizontal and vertical and knowing the average vibration produced Using equation (1), (2) and (3).

\subsection{Lister powered block moulding machine.}

The noise induced on lister power block moulding machine was measured and recorded for duration of 20 seconds. The idle noise produced by leister power block moulding machine was measured and recorded. The production noise produced by leister power block moulding machine was measured and recorded. The vibration produced by leister power block moulding machine was measured three times for duration of 20 seconds and recorded, this vibration was taken vertical, horizontal and axially and assessing the average vibration produced.

\subsection{QTJ4-40 block moulding machine}

The noise produced by QTJ4-40 interlocking block making machine was measured three times for the duration of 20seconds and recorded. The idle noise produced by QTJ440 block moulding machine was measured and recorded. The production noise was measured on QTJ4-40 block moulding machine.

\subsection{Vibration meter}

In order to determine the activities during which the operator was exposed to vibration, as well as duration of the individual activity during ordinary working day and the value of the vibration produced was carried out by the use of the vibration meter and the stopwatch to measure the time duration.

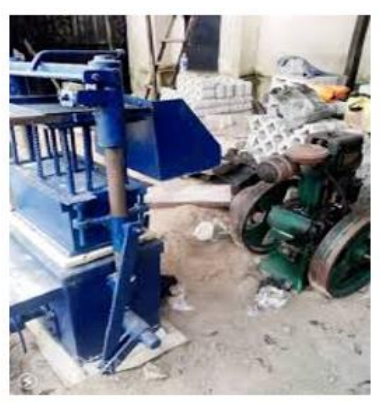

Lister Block Moulding Machine

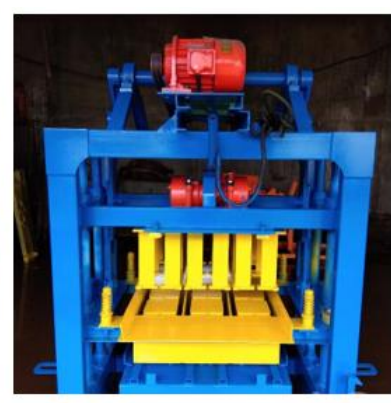

QTJ4-40 Block Moulding Machine

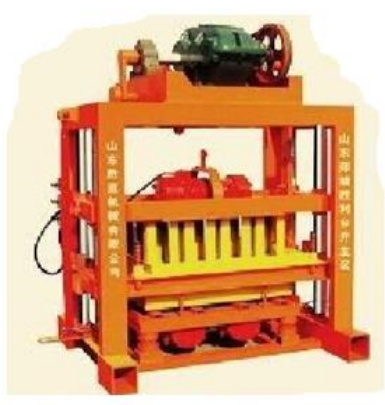

LM2-45 Block Moulding Machine

Plate 1. 


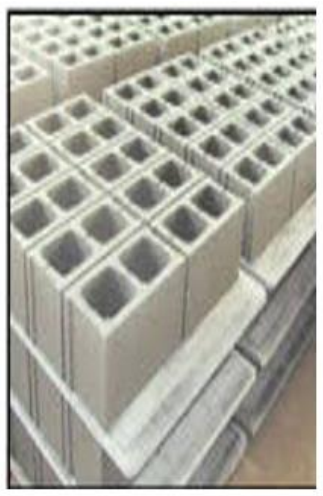

Block

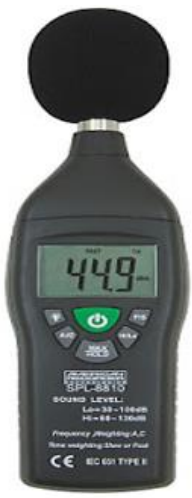

Sound level Meter

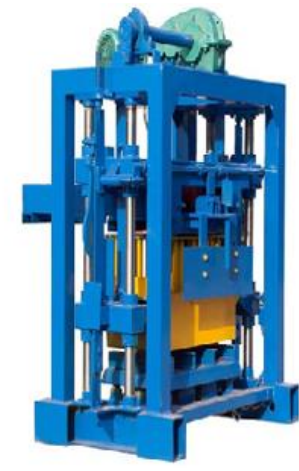

QT40B Moulding Machine

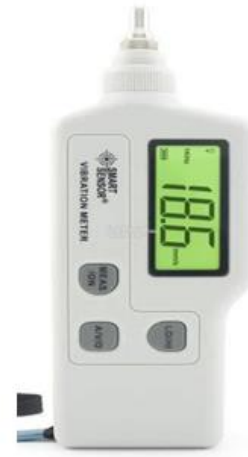

Vibration Meter

Plate 2.

\section{Results and Discussion}

\subsection{Production Noise}

Results of Noise generated in the course of production of six and nine inches block of QT40B, QTJ4-40, Lister, and LM2-45 machines are as presented below:

\subsubsection{Idle Noise of block machines}

Figure 1 shows the idle noise level of the QT40B, QTJ4-40, Lister, and LM2-45 machines used for the production of six and nine inches' sand Crete blocks. The LM2-45 has the highest range idle noise of $86.71 \mathrm{db}$, followed by the Lister with $82.51 \mathrm{db}$, then the QT40B with 78.1 db and lastly the QTJ4-40 with 70.3db. The implication is that, this level of noise already above the acceptable limit allowed [11-13] and consequently require noise production equipment for workers in such environments.

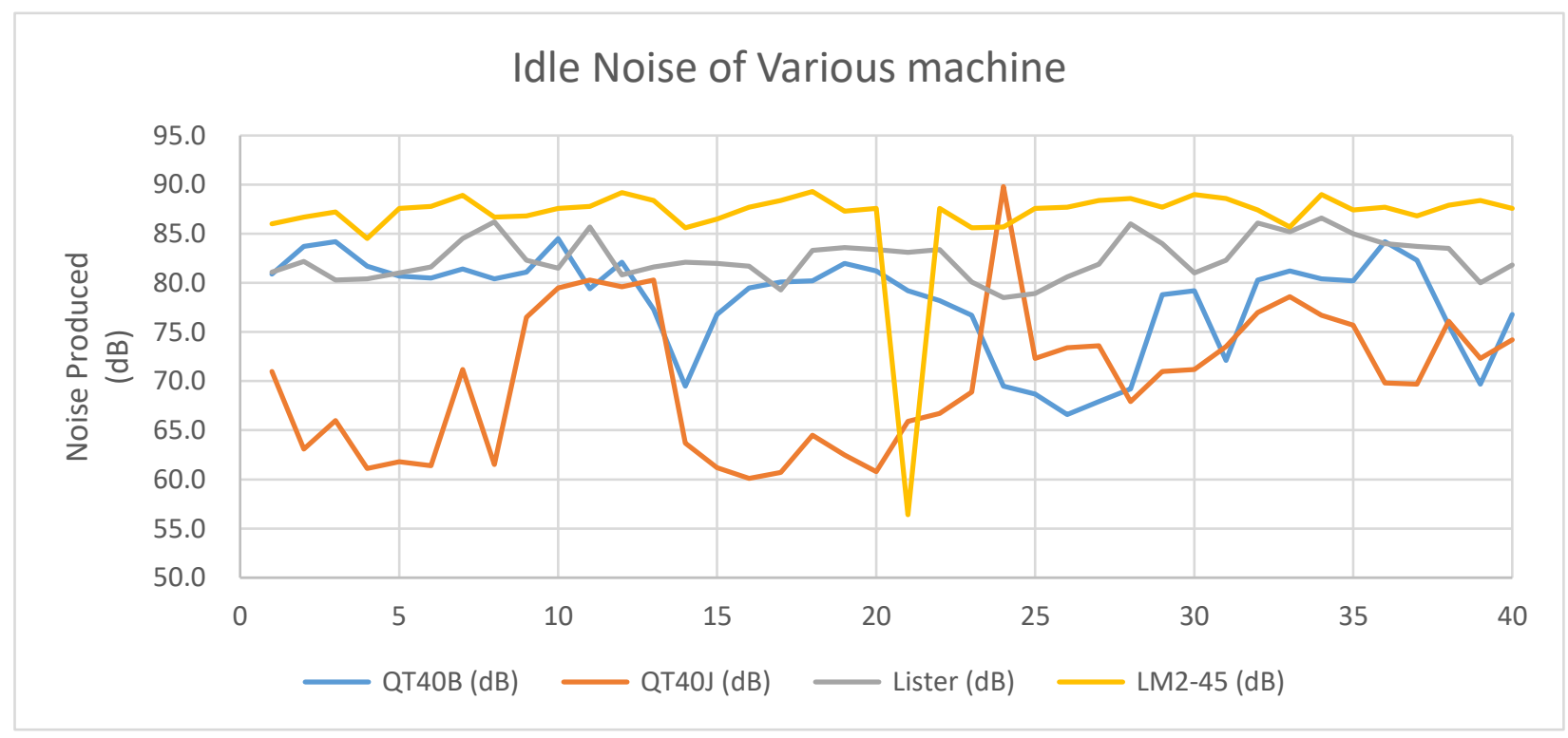

Figure 1. Idle Noise of QT40B, QTJ4-40, Lister and LM2-45 machines.

\subsubsection{Production noise for six inches' block}

Figure 2 shows the noise generated by QT40B, QTJ4-40, Lister and LM2-45 block moulding machines for the production of six inches' block looking at their averages, the QTJ4-40 machines produces the least noise with an average of 96.8db, The LM2-45 block 
moulder generates $99.20 \mathrm{db}$, the Lister block moulder produces $107.11 \mathrm{db}$, while the light amount of noise is generated by the QT40B which is $108.4 \mathrm{db}$.

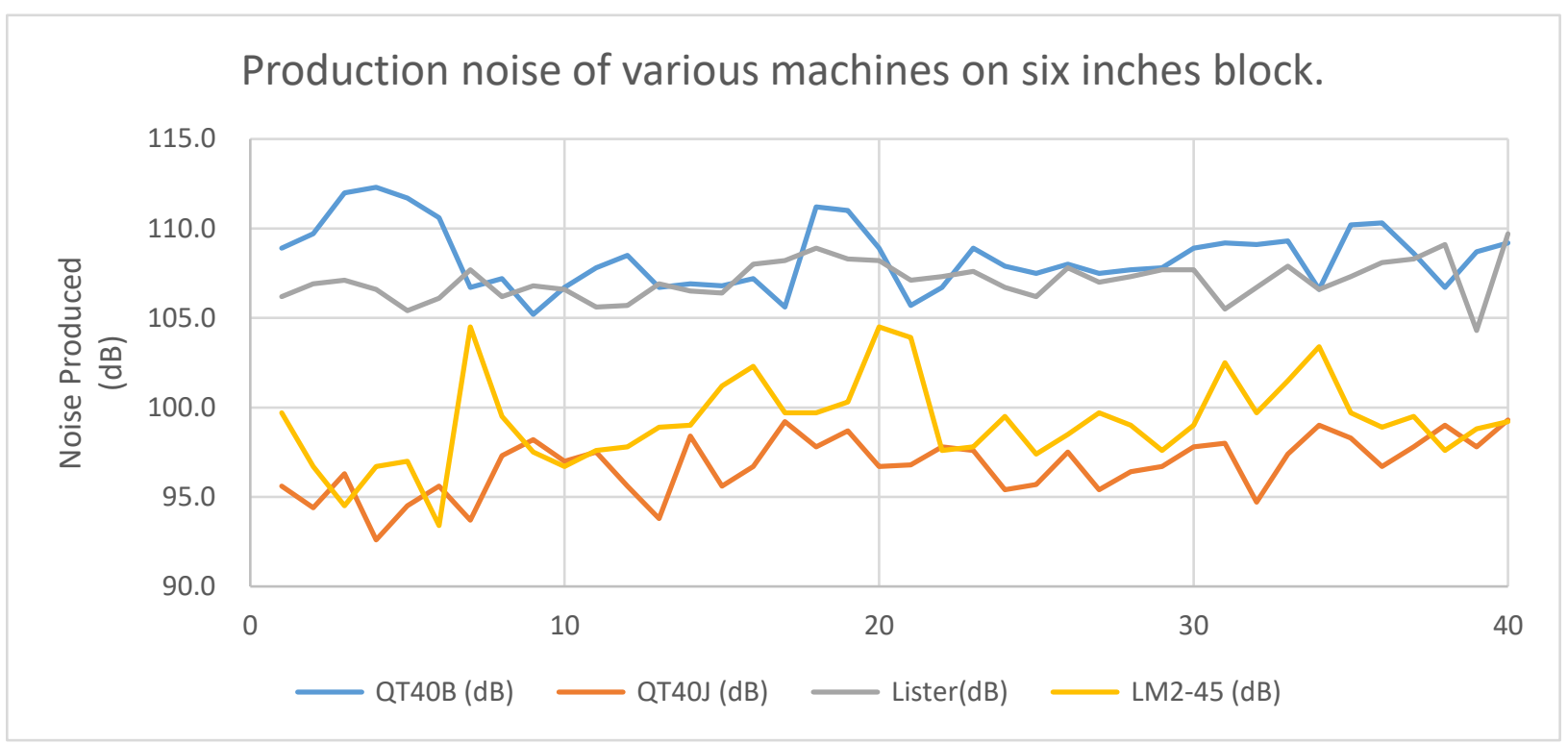

Figure 2. Production noise of QT40B, QTJ4-40, Lister and LM2-45 machines on 6 inches' block.

\subsubsection{Production noise for nine inches' blocks}

Figure 3 shows the noise quantity generated by QT40B, QTJ4-40, Lister and LM2-45 block moulding machines for the production of nine inches' block looking at their averages, the LM2-45 machines produce the least noise with an average of $105.31 \mathrm{db}$, The QTJ440 block moulder generates $107.3 \mathrm{db}$, the Lister block moulder produces $109.96 \mathrm{db}$, while the light amount of noise is generated by the QT40B which is $110.5 \mathrm{db}$.

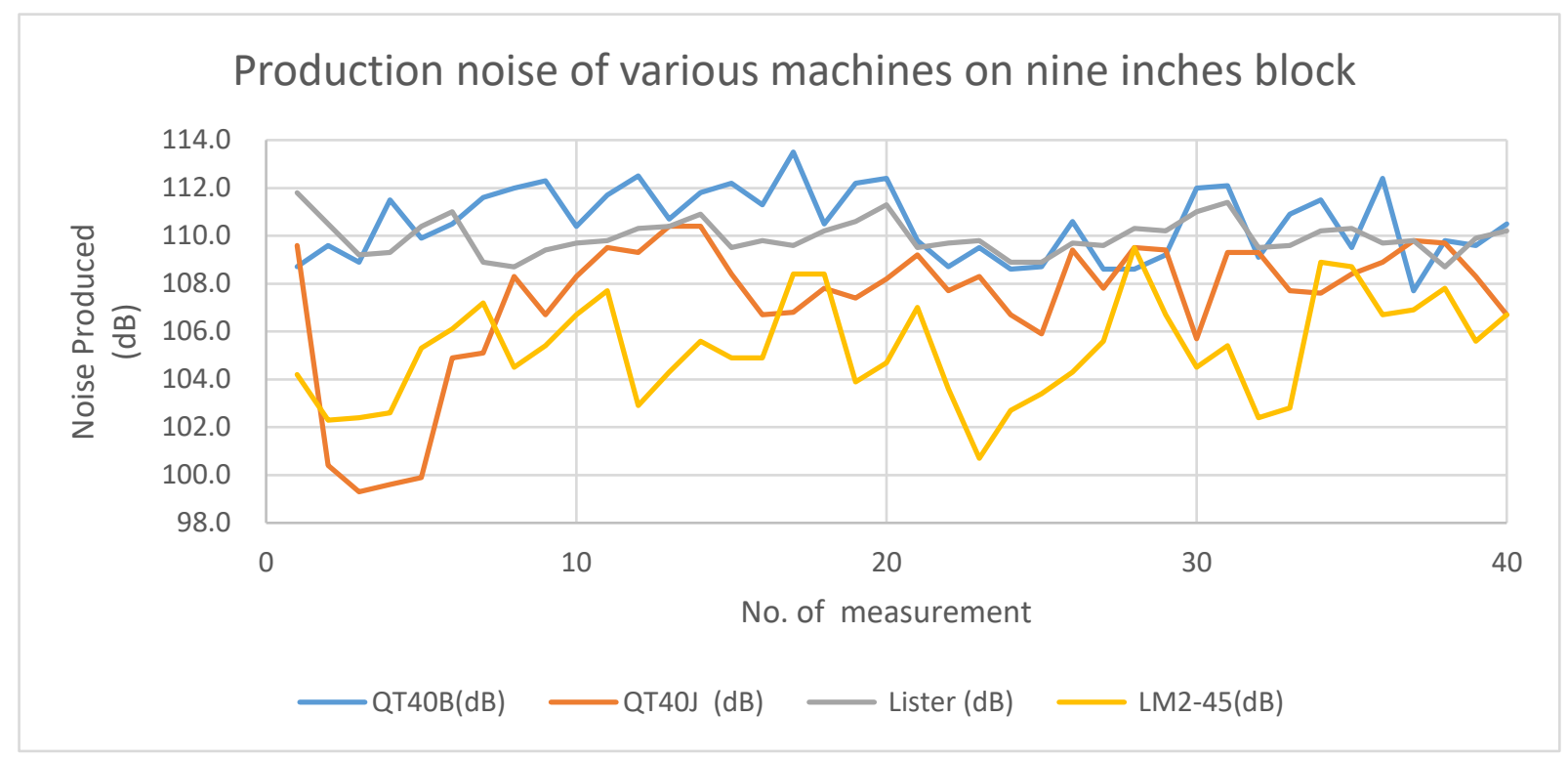

Figure 3. Production noise of QT40B, QTJ4-40, Lister and LM2-45 machines on nine inches' block.

\subsection{Production vibration}

\subsubsection{Idle vibration of block moulders}


Figure 4 shows the idle vibration level of the QT40B, QTJ4-40, Lister, and LM2-45 machines used for the production of six and nine inches' sand Crete blocks. The Lister has the highest range idle vibration of $2.8 \mathrm{~ms}^{-2}$, followed by the QTJ4-40 with $2.3 \mathrm{~ms}^{-2}$, then the LM2-45 with $2.0 \mathrm{~ms}^{-2}$ and lastly the QT40B with $1.9 \mathrm{~ms}^{-2}$. The implication is that, this level of vibration is already below the acceptable limit value allowed in the Directive 44/EC from 2002 - on the Minimum Health and Safety Requirements Regarding to Exposure of Workers to the Risk Arising from Physical Agents vibration.

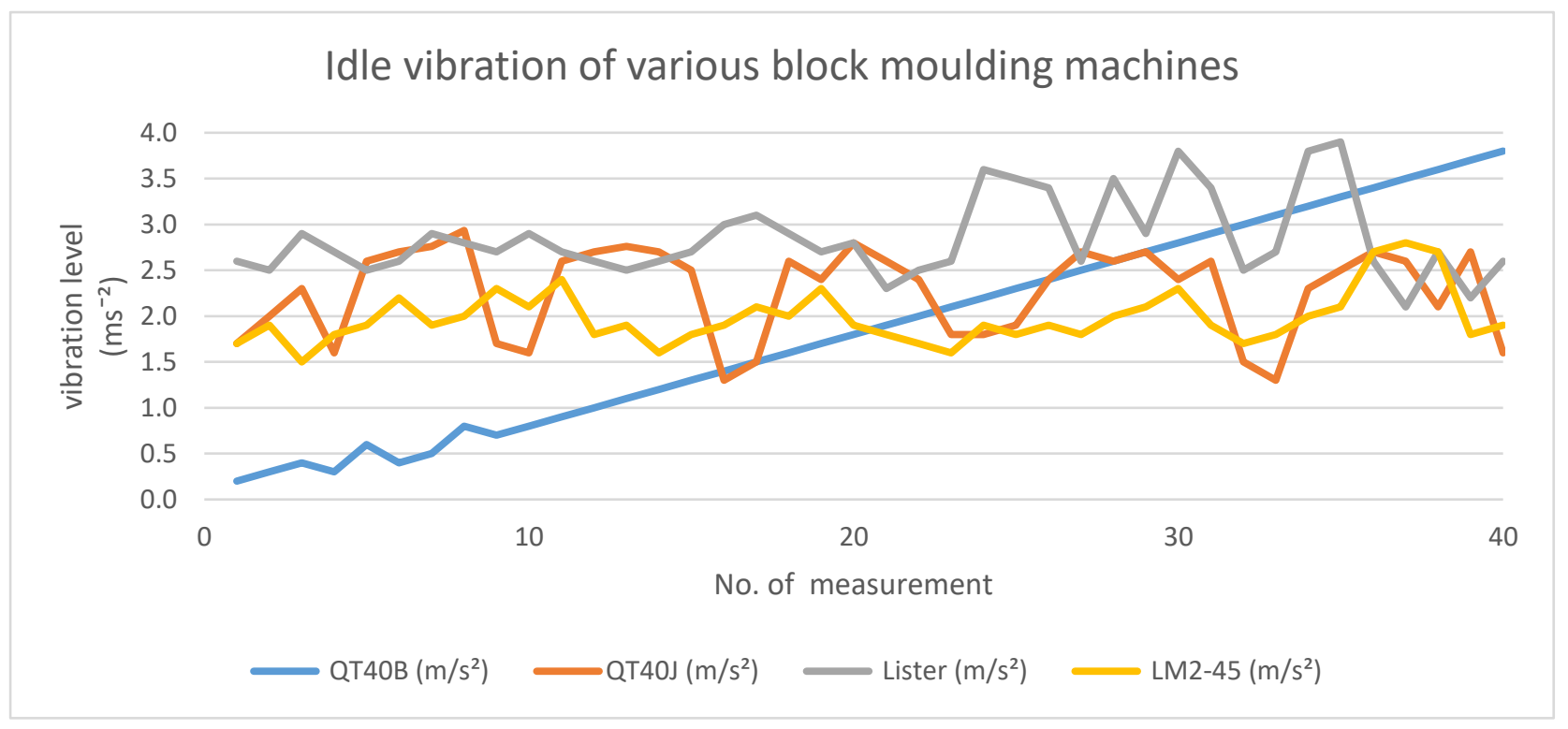

Figure 4. Idle vibration of QT40B, QTJ4-40, Lister and LM2-45 block moulding machines.

\subsubsection{Production vibration for six inches' block}

Figure 5 shows the vibration generated by QT40B, QTJ4-40, Lister and LM2-45 block moulding machines for the production of six inches' block looking at their averages, the LM2-45 machines produce the least vibration with an average of $33.6 \mathrm{~ms}^{-2}$, The QT40B block moulder generates $36.7 \mathrm{~ms}^{-2}$, the Lister block moulder produces $40.0 \mathrm{~ms}^{-2}$, while the light amount of vibration is generated by the QTJ4-40 which is $155.1 \mathrm{~ms}^{-2}$.

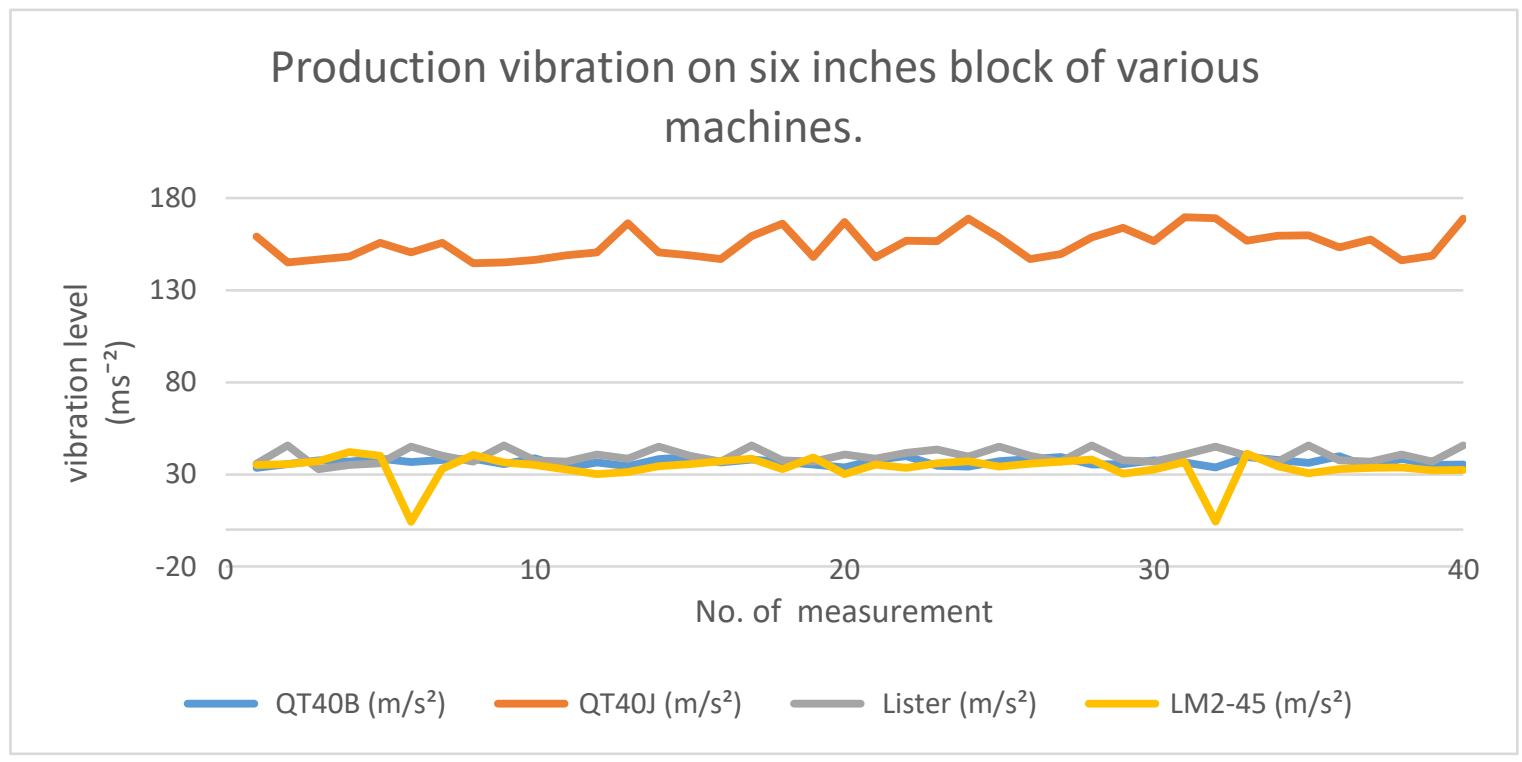

Figure 5. Production vibration on 6 inches block of QT40B, QTJ4-40, Lister and LM2-45 machines. 


\subsubsection{Production vibration for nine inches' blocks}

Figure 6 shows the vibration generated by QT40B, QTJ4-40, Lister and LM2-45 block moulding machines for the production of nine inches' block looking at their averages, the QT40B machines produces the least vibration with an average of $45.7 \mathrm{~ms}^{-2}$, The LM2-45 block moulder generates $49.1 \mathrm{~ms}^{-2}$, the Lister block moulder produces $60.0 \mathrm{~ms}^{-2}$, while the high amount of vibration is generated by the QTJ4-40 which is $162.2 \mathrm{~ms}^{-2}$.

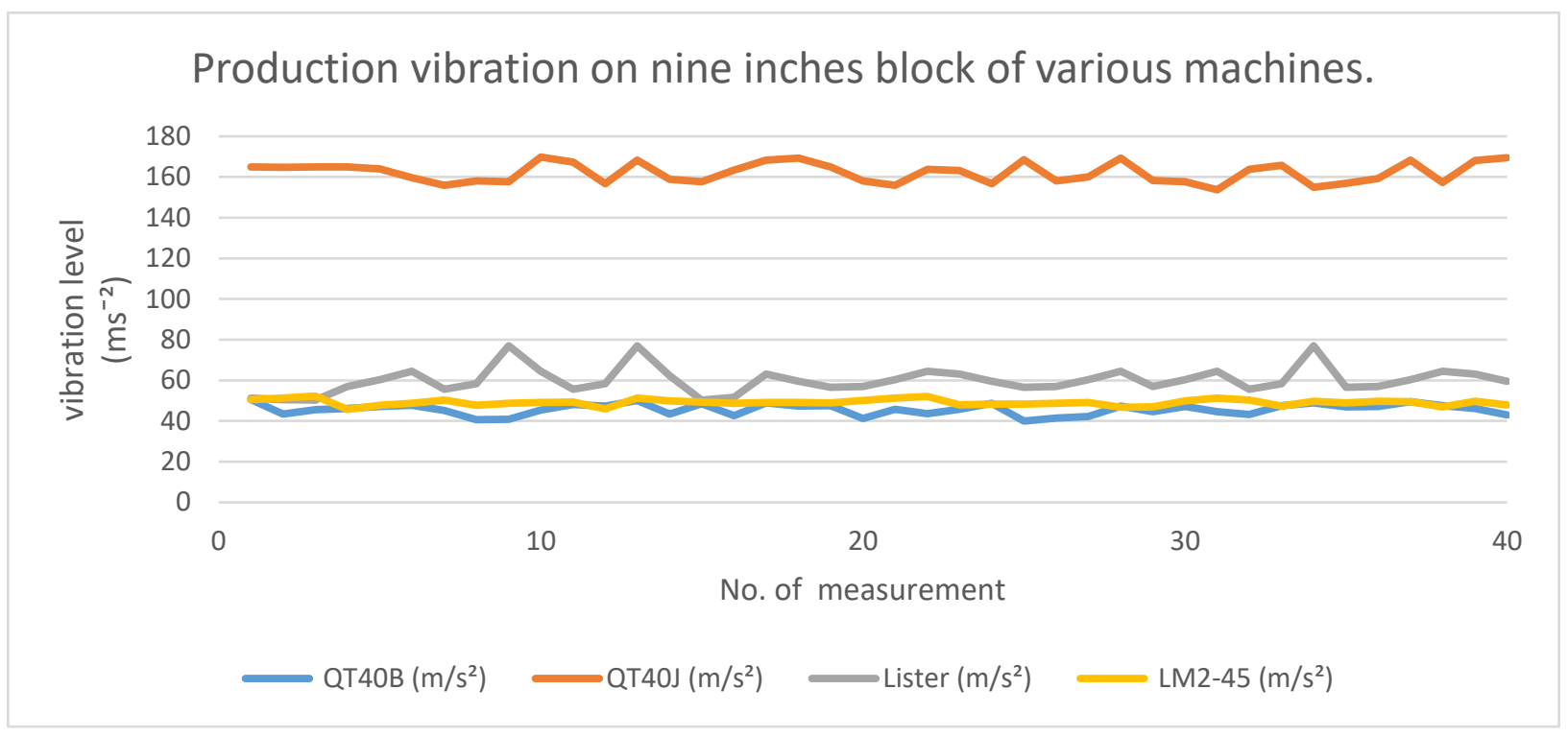

Figure 6. Production vibration on nine inches block of QT40B, QTJ4-40, Lister and LM2-45 machines.

\subsubsection{Vibration induced on worker during production of six inches' block}

Figure 7 shows the vibration generated by QT40B, QTJ4-40, Lister and LM2-45 block moulding machines for the production of six inches' block looking at their averages, the LM2-45 machine produces the least vibration with an average of $2.9 \mathrm{~ms}^{-2}$, The QT40B block moulder generates $8.1 \mathrm{~ms}^{-2}$, the Lister block moulder produces $9.0 \mathrm{~ms}^{-2}$, while the high amount of vibration is generated by the QTJ4-40 which is $19.2 \mathrm{~ms}^{-2}$.

The implication is that, this level of vibration is already at some point above the acceptable limit value allowed in the Directive 44/EC from 2002 - on the Minimum Health and Safety Requirements Regarding to Exposure of Workers to the Risk Arising from Physical Agents vibration. 


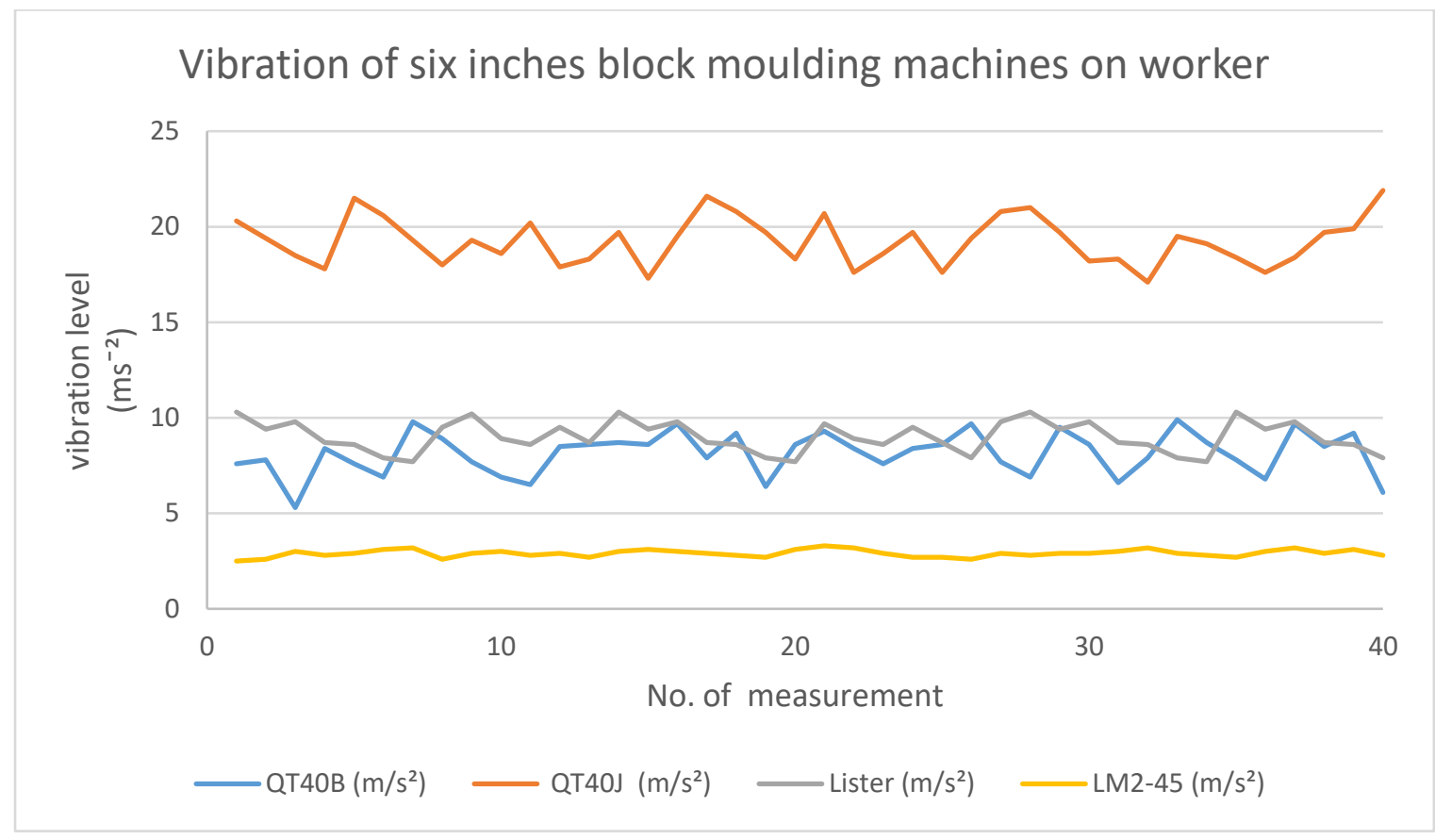

Figure 7. Vibration of QT40B, QTJ4-40, Lister and LM2-45 block moulding machines on worker during six inches block production.

\subsubsection{Vibration induced on worker during production of nine inches' block}

Figure 8 shows the vibration generated by QT40B, QTJ4-40, Lister and LM2-45 block moulding machines for the production of nine inches' block looking at their averages, the LM2-45 machine produces the least vibration with an average of $4.7 \mathrm{~ms}^{-2}$, The QT40B block moulder generates $12.1 \mathrm{~ms}^{-2}$, the Lister block moulder produces $18.3 \mathrm{~ms}^{-2}$, while the high amount of vibration is generated by the QTJ4-40 which is $26.3 \mathrm{~ms}^{-2}$.

The implication is that, this level of vibration is already at above the acceptable limit value allowed in the Directive 44/EC from 2002 - on the Minimum Health and Safety Requirements Regarding to Exposure of Workers to the Risk Arising from Physical Agents vibration.

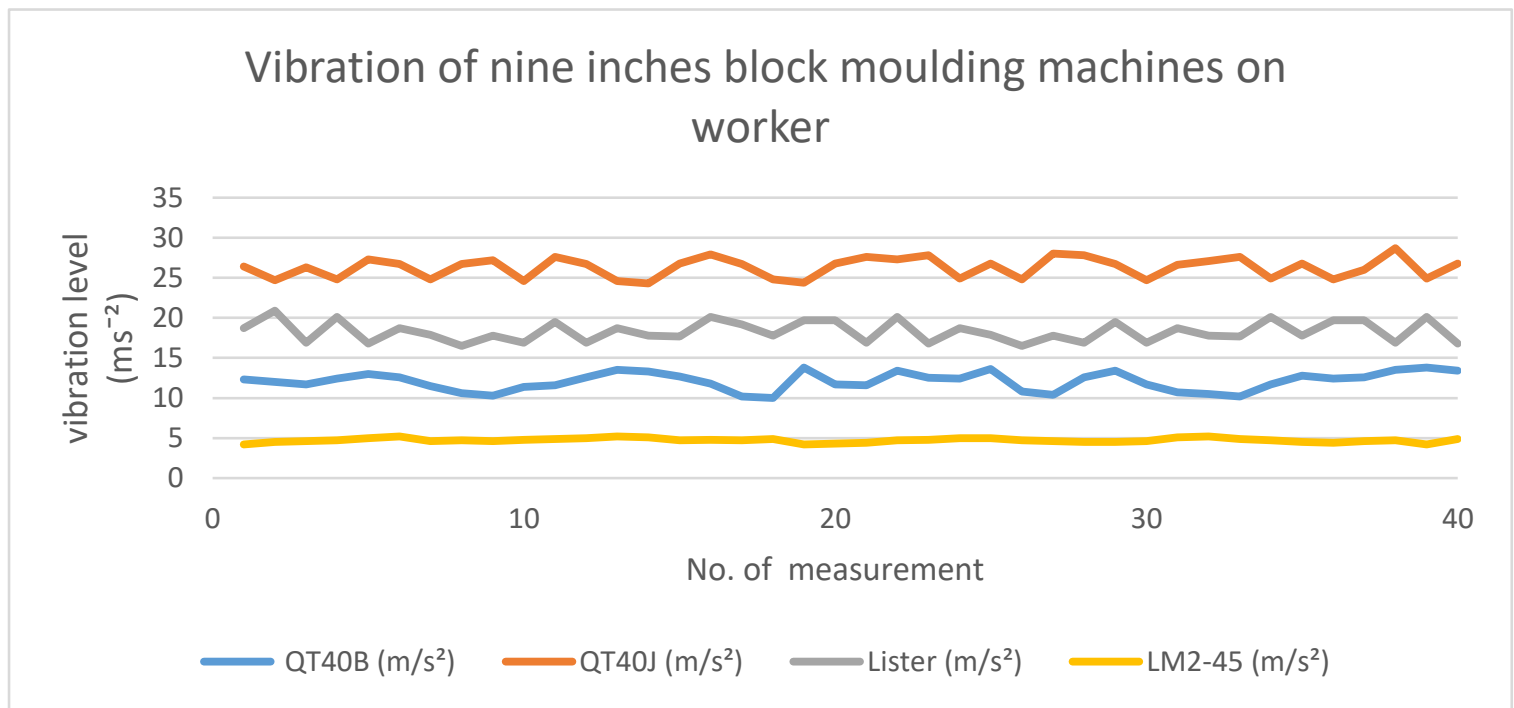

Figure 8. Vibration QT40B, QTJ4-40, Lister and LM2-45 block moulding machines on worker during nine inches block production. 


\section{Conclussion and Recommendation}

\subsection{Conclussion}

This research was carried out to analyze the noise and vibration exposure level at work on QT40, QTJ4-40, lister and LM2-45 operators. The results show that workers were exposed to noise levels above $85 \mathrm{~dB}$ and vibration levels above $5 \mathrm{~ms}^{-2}$ set as upper limit values in the Directive 44/EC from 2002 - on the Minimum Health and safety Requirements Regarding to Exposure of Workers to the Risk Arising from Physical Agents Vibration.

This investigation reveals that noise levels at 30 of 42 measurement points exceeded the recommended limit of $82 \mathrm{~dB}(\mathrm{~A})$ by values of 1-27 dB (A). Furthermore, discomfort and irritation being caused by the pollution can drastically reduce productivity. In addition, some operators may soon reach the threshold of pains and lead to permanent loss of hearing and death.

Due to these possible adverse effects of noise and vibration pollution on the populace, a number of action plans can be taken to abate the environmental Noise and vibration pollution in Nigeria. These include technical, planning, behavioral, and educational solutions.

\subsection{Recommendation}

To reduce the induced noise and the transmission of vibration to the worker by engineering the equipment and enhance workplace and productivity the following are recommended.

1. Maintain equipment properly (i.e., balance and replace worn parts)

2. Use materials that generate less noise and vibration.

3. Use of safety boat and gloves to reduce the vibration transmitted through leg and hands.

4. Use headset or ear protecting pads to reduce noise induce to the ears.

\section{References}

[1] NIOSH (1996) National occupational research agenda. National Institute of Occupational Safety and Health, (NIOSH) Pub. No. 96-115. Cincinnati, OH.

[2] WHO (2001) WHO guideline on Community Noise (Ed.) Dietrich Schwela. TRB Session 391,

[3] Saadu, A. A. (1988). Community and occupational noise survey and analysis of some selected WHO Geneva, Switzerland. tries. Ph.D. thesis, University of Benin, Nigeria.

[4] Passchier-Vermeer, W, and Passchier, W. F. (200). Noise exposure and public health, Environmental Health Perspectives,108 (supplement 1), 123-131.

[5] World Health Organization (2005) Occupational and community noise. WHOOMS. http://www.who.int.inffs/en /facthtmal. (Accessed May 2020).

[6] Ologe, E.F Akande, M.T and Olajide G.T. (2005). Noise exposure, awareness, attitudes and use of hearing protection in a steel rolling mill in Nigeria. Occupational Medicine 55:487-489.

[7] Bovenzi, M. (2006). Health risks from occupational exposures to mechanical vibration. La Med del Lavoro 97(3):535-541

[8] Ighoroje ADA, Marchie C, Nwobodo ED (2004) Noise-induced hearing impairment as an occupational risk factor among Nigeria traders. Nigerian Journal of Physiological Sciences 19(1-2), 14-19

[9] Cann AP, Salmoni AW, Vi P, Eger TR (2003). An exploratory study of whole-body vibration exposure and dose while operating heavy equipment in the construction industry. Appl Occup Environ Hyg 18(12):999-1005

[10] Boateng CA, Amedofu GK (2004) Industrial noise pollution and its effects on the capabilities of workers: a study from saw mills, printing presses and cornmills. African J Health Sci11, 1-2.

[11] Ydego M (1991) Assessment of noise pollution in Friendship textile mill Ltd, Ubango-Dares $\quad$ Salaam. Environmental Engineering17, 479-485.

[12] Onuu MU, Taiwo AN (2005) Industrial noise studies in quarries and neighboring communities. International Journal of Natural and Applied Sciences (IJNAS) 1(1), $94-100$.

[13] Oyedepo, S. O., \& Saadu, A. A. (2008). Changing noise climate of Ilorin metropolis. Environmental Engineering Science, 25(6), 797-808. 